Original Article

\title{
Effects of compound music program on cognitive function and QOL in community-dwelling elderly
}

\author{
TakaAki Fujita, MS ${ }^{1)} a^{*}$, Akemi Ito, MS ${ }^{1) a}$, Nana KikUChi ${ }^{2)}$, Tomohiro Kakinuma, PhD ${ }^{3)}$, \\ Yoshinisa SATo, $\mathrm{PhD}^{1)}$
}

1) Department of Rehabilitation, Faculty of Health Sciences, Tohoku Fukushi University: 1-8-1 Kunimi, Aoba-ku, Sendai-shi, Miyagi 981-8522, Japan

2) Nursing Care Homes for the Elderly Yuga, Japan

3) Department of Health Care Administration and Management, Faculty of Health Sciences, Tohoku Fukushi University, Japan

\begin{abstract}
Purpose] Interventions using music, physical exercise, and reminiscence therapy are widely used both for rehabilitation and care of the elderly. This study aimed to investigate the effect of structured interventions comprising music, physical exercise, and reminiscence therapy on cognitive function and quality of life of the community-dwelling elderly. [Subjects and Methods] The study included 15 community-dwelling elderly people who used a day-care center. Participants underwent sessions comprising the following three factors: 1) singing songs familiar to the elderly; 2) physical exercise to music; and 3) observation of historical pictures. Sessions were conducted once or twice per week, 30 to 40 min per day, for 10 weeks. Pre and post interventions of the Mini Mental State Examination, the Behavioral Rating Scale for the Elderly, and the SF-8 were compared. [Results] No significant difference was observed between pre- and post-intervention scores on the Mini Mental State Examination and the Behavioral Rating Scale for the Elderly. However, the post intervention physical component summary of SF- 8 was significantly higher than the pre intervention summary. [Conclusion] This study suggests that interventions comprising music, physical exercise, and reminiscence therapy may contribute toward the improvement of elderly individuals' healthrelated quality of life, especially physical health.

Key words: Music, Reminiscence therapy, Elderly
\end{abstract}

(This article was submitted Jun. 20, 2016, and was accepted Jul. 29, 2016)

\section{INTRODUCTION}

Intervention through music is widely used in the rehabilitation and care of the elderly. A previous study reported that singing affects the mental health and oral function of the elderly ${ }^{1)}$ and that listening to music or singing is effective in improving cognitive function ${ }^{2)}$ and quality of life $(\mathrm{QOL})^{2}$, and reducing anxiety ${ }^{3)}$ in elderly individuals with dementia. Some recent reports suggested that interventions combining music and physical exercise were more effective than listening to music alone. For example, Sakamoto et al. ${ }^{4}$ reported that, in individuals with dementia, an interactive music intervention in which individuals listened to music and clapped, sang, and danced affected the improvement of behavioral and psychological symptoms of dementia (BPSD) more than a passive music listening group. In addition, Satoh et al. ${ }^{5)}$ reported that physical exercise combined with music produced more positive effects on the cognitive function of elderly individuals than exercise alone. Thus, these findings suggest that the combination of music and physical exercise more effectively improves cognitive function, BPSD, and QOL in people with dementia or the elderly.

Reminiscence therapy (RT) also affects cognitive function, BPSD, and QOL in elderly individuals with and without dementia $^{6-9}$. In RT, people speak about their experiences or memories in a group using pictures as clues. Combining RT with

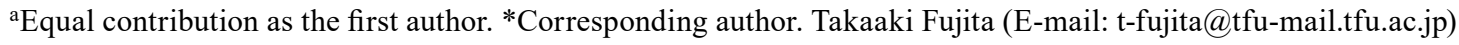

(C2016 The Society of Physical Therapy Science. Published by IPEC Inc.

This is an open-access article distributed under the terms of the Creative Commons Attribution Non-Commercial No Derivatives (by-nc-nd) License $<$ http://creativecommons.org/licenses/by-nc-nd/4.0/>. 
the music and physical exercise combination mentioned above may be more effective in the elderly and in individuals with dementia. However, no previous research has investigated the effects of interventions comprising music, physical exercise, and RT. Therefore, this study aimed to investigate the effect of structured interventions that comprised music, physical exercise, and RT on cognitive function and QOL in the elderly.

\section{SUBJECTS AND METHODS}

Participants included 15 community-dwelling elderly people who used a day-care center (Table 1). All participants signed an informed consent form prior to participation. The study protocol was approved by the Tohoku Fukushi University's institutional ethics review board.

Structured interventions comprising music, physical exercise, and RT were conducted for participants. Their cognitive function and QOL were compared before and after interventions. Each session included the following three factors: 1) singing songs familiar to the elderly or matched seasons; 2) physical exercise to music; and 3) observation of historical pictures. Participants could see the song lyrics, demonstrations of physical exercises, and historical pictures on a big monitor in front of them. Under the recreation instructors' instructions, sessions were conducted by an occupational therapist or care staff. They conducted sessions using a music device and facilitated participant interaction. On observing historical pictures, participants were requested to share their memories. Participants received intervention once or twice per week, 30 to 40 min per day, for 10 weeks.

Participants were assessed using the Mini Mental State Examination (MMSE) ${ }^{10)}$, the Behavioral Rating Scale for the Elderly ${ }^{11)}$, and the Japanese version of the Medical Outcome Study Short Form 8-Item Health Survey (SF-8) ${ }^{12}$. The MMSE was used to assess cognitive function while the Behavioral Rating Scale for the Elderly was used to assess vital function at home. SF-8 was used to assess health-related QOL. All assessments were conducted by occupational therapists. The Wilcoxon signed-rank test was performed to compare each pre and post intervention score. The SPSS Statistics 22.0 (IBM, Chicago, IL, USA) was used as the statistical software and the level of significance was set at 5\%.

\section{RESULTS}

Table 2 outlines the outcomes of each assessment. No significant difference was observed between pre- and post-intervention scores on the MMSE and the Behavioral Rating Scale for the elderly. However, the post-intervention physical component summary of SF-8 was significantly higher than the pre-intervention summary $(\mathrm{p}<0.05)$.

\section{DISCUSSION}

This study suggests that interventions comprising music, physical exercise, and RT could contribute toward improving community-dwelling elderly individuals' health-related QOL, especially their physical health. In SF-8, the average values for Japanese individuals with respect to the "physical component summary score" and the "mental component summary score" of 70-79 year-old individuals (the oldest age group to be examined) were 44.78 and 50.95 points, respectively ${ }^{12)}$; as the participants' scores in this study were 42.2 and 51.0 points, respectively, little difference was observed between the two. Post

Table 1. Characteristics of study participants

\begin{tabular}{lc}
\hline & Mean \pm SD \\
\hline Age (years) & $84.3 \pm 6.6$ \\
Female (\%) & 86.6 \\
Diagnosis of dementia (\%) & 26.6 \\
Able to walk (\%) & 93.3 \\
\hline
\end{tabular}

Table 2. Comparison of each evaluation score by pre-post intervention

\begin{tabular}{lcc}
\hline & Pre & Post \\
\hline Mini mental state examination & $20.8 \pm 5.7$ & $20.9 \pm 5.9$ \\
Behavioral Rating Scale for the Elderly & $119.7 \pm 22.8$ & $121.0 \pm 28.3$ \\
SF-8 & & \\
Physical component summary & $42.2 \pm 10.9$ & $48.1 \pm 7.5^{*}$ \\
Mental component summary & $51.0 \pm 9.0$ & $51.8 \pm 5.8$ \\
\hline$* \mathrm{p}<0.05$ & &
\end{tabular}


intervention, the "physical component summary score" showed an improvement, and this score was higher than the national average value for 70-79 year-old individuals. Previous studies have reported that listening, singing, and RT improve QOL of individuals with dementia ${ }^{2,9}$. As our intervention included these three factors, we could provide relative improvement in QOL in short sessions. However, our study had no control group. Therefore, we cannot refer to the relevance between each factor and its effect and further studies are required to examine the same.

Physical therapists have an important role to play in not only improving physical functions but also the QOL of patients. Previous studies reported that experiencing a fall or pain was associated with a low health-related QOL related to bodily functions ${ }^{13)}$. Some studies also reported that physical exercise can have beneficial effects on the "physical component summary score" of SF-8 in the community-dwelling elderly ${ }^{14}$. However, there are cases where it is difficult to clinically carry out continual aggressive physical exercise due to various reasons such as pain, disease, or motivation in the elderly. In such cases, the intervention used in this study may be useful to improve health-related QOL related to bodily functions in the elderly.

On the other hand, our intervention did not affect cognitive and vital functions. Our results indicated that using music improved QOL but did not improve cognitive function; the results thus corresponded with a previous study by Choi ${ }^{15)}$. The relationship between interventions using music and improvement of cognitive function is as yet unclear. For example, some research results did indicate that interventions using music showed effects on the improvement of vital functions including cognitive function and BPSD in elderly people with and without dementia ${ }^{1,2,16-19)}$. However, other results do not indicate such significant effects on these functions ${ }^{13,20,21)}$. It is assumed that these differences are associated with the variations in the duration of the interventions and the level of participants' cognitive function. It is possible that the duration of the intervention in our study was shorter and thus did not affect people's cognitive and vital functions. Therefore, it is necessary to investigate long-term intervention effects in future studies.

This study has some limitations. First, the participants of this study belonged only to one facility. Second, the study used small samples. Third, we did not verify carry-over effects data. Therefore, long-term intervention studies that include more number of participants and use a control group are required.

\section{ACKNOWLEDGEMENT}

This study was supported by a grant from the MEXT-Supported Program for the Strategic Research Foundation at Private Universities (2012-2016).

\section{REFERENCES}

1) Sakano K, Ryo K, Tamaki Y, et al.: Possible benefits of singing to the mental and physical condition of the elderly. Biopsychosoc Med, 2014, 8: 11. [Medline] [CrossRef]

2) Särkämö T, Tervaniemi M, Laitinen S, et al.: Cognitive, emotional, and social benefits of regular musical activities in early dementia: randomized controlled study. Gerontologist, 2014, 54: 634-650. [Medline] [CrossRef]

3) Sung HC, Chang AM, Lee WL: A preferred music listening intervention to reduce anxiety in older adults with dementia in nursing homes. J Clin Nurs, 2010, 19: 1056-1064. [Medline] [CrossRef]

4) Sakamoto M, Ando H, Tsutou A: Comparing the effects of different individualized music interventions for elderly individuals with severe dementia. Int Psychogeriatr, 2013, 25: 775-784. [Medline] [CrossRef]

5) Satoh M, Ogawa J, Tokita T, et al.: The effects of physical exercise with music on cognitive function of elderly people: Mihama-Kiho project. PLoS One, 2014, 9: e95230. [Medline] [CrossRef]

6) Wang JJ: The effects of reminiscence on depressive symptoms and mood status of older institutionalized adults in Taiwan. Int J Geriatr Psychiatry, 2005, 20: 57-62. [Medline] [CrossRef]

7) Woods B, Spector A, Jones C, et al.: Reminiscence therapy for dementia. Cochrane Database Syst Rev, 2005, 18: CD001120. [Medline]

8) Sok SR: Effects of individual reminiscence therapy for older women living alone. Int Nurs Rev, 2015, 62: 517-524. [Medline] [CrossRef]

9) O'Shea E, Devane D, Cooney A, et al.: The impact of reminiscence on the quality of life of residents with dementia in long-stay care. Int J Geriatr Psychiatry, 2014, 29: 1062-1070. [Medline] [CrossRef]

10) Folstein MF, Folstein SE, McHugh PR: "Mini-mental state". A practical method for grading the cognitive state of patients for the clinician. J Psychiatr Res, 1975, 12: 189-198. [Medline] [CrossRef]

11) Nakazato K, Shimonaka Y, Narita K, et al.: [Development of behavior rating scale for the elderly]. Nippon Ronen Igakkai Zasshi, 1991, 28: 790-800. [Medline] [CrossRef]

12) Fukuhara S, Suzukamo Y: Manual of the SF-8 Japanese version. Kyoto: Institute for Health Outcome \& Process Evaluation Research, 2004 (in Japanese).

13) Furuta Y, Suzuki M: Association of the health-related quality of life with falls and pain among community-based elderly individuals: a cross-sectional study. Jpn J Fall Prev, 2016, 2: 41-48 (in Japanese).

14) Otao H, Tanaka S, Tumiyama W, et al.: Effects of a fall prevention program on physical functions, health-related QOL, and exercise habits. Jpn J Health Promot Phys Ther, 2014, 4: 25-30 (in Japanese). [CrossRef]

15) Choi AN, Lee MS, Cheong KJ, et al.: Effects of group music intervention on behavioral and psychological symptoms in patients with dementia: a pilotcontrolled trial. Int J Neurosci, 2009, 119: 471-481. [Medline] [CrossRef] 
16) Li YH, Chen SM, Chou MC, et al.: [The use of music intervention in nursing practice for elderly dementia patients: a systematic review]. Hu Li Za Zhi, 2014, 61: 84-94. [Medline]

17) Ueda T, Suzukamo Y, Sato M, et al.: Effects of music therapy on behavioral and psychological symptoms of dementia: a systematic review and meta-analysis. Ageing Res Rev, 2013, 12: 628-641. [Medline] [CrossRef]

18) Sung HC, Lee WL, Li TL, et al.: A group music intervention using percussion instruments with familiar music to reduce anxiety and agitation of institutionalized older adults with dementia. Int J Geriatr Psychiatry, 2012, 27: 621-627. [Medline] [CrossRef]

19) Han P, Kwan M, Chen D, et al.: A controlled naturalistic study on a weekly music therapy and activity program on disruptive and depressive behaviors in dementia. Dement Geriatr Cogn Disord, 2010, 30: 540-546. [Medline] [CrossRef]

20) Van de Winckel A, Feys H, De Weerdt W, et al.: Cognitive and behavioural effects of music-based exercises in patients with dementia. Clin Rehabil, 2004, 18: 253-260. [Medline] [CrossRef]

21) Cooke ML, Moyle W, Shum DH, et al.: A randomized controlled trial exploring the effect of music on agitated behaviours and anxiety in older people with dementia. Aging Ment Health, 2010, 14: 905-916. [Medline] [CrossRef] 